\title{
Cardiorespiratory fitness in adolescents with obesity: a 6-month follow-up study
}

\author{
Aptidão Cardiorrespiratória em Adolescentes com obesidade: um estudo \\ de seguimento de 6 meses
}

Daniel Calado Brito'; Antonio Henrique Germano-Soares'; Thiago Ricardo dos santos Tenório'; Mara Cristina Lofrano-Prado²; Nelson Nardo Junior; José Donato Junior²; Marcos André Moura dos Santos ${ }^{1}$; Camila Tenório Calazans de Lira'; Caio Machado Terra4; Wagner Luiz do Prado ${ }^{1,4}$.

\begin{abstract}
The aim of this study was to investigate whether the effects of a multidisciplinary intervention on cardiorespiratory fitness are maintained after 6-month follow-up in adolescents with obesity. One-hundred and seven adolescents with obesity were intentionally allocated in two groups: experimental or control. Adolescents in experimental group underwent a multidisciplinary intervention (supervised aerobic exercise, psychological, nutritional, and clinical counseling). Cardiorespiratory fitness (direct gas analysis), body composition (dual-energy-DXA), anthropometry and blood lipids were measured before intervention (baseline), at the end of the 24-week intervention (post-intervention) and six months after the end of the intervention (follow-up). Cardiorespiratory fitness reduced in control group with no changes in experimental group, and these differences were maintained in the follow-up assessment (control group: $24.2 \pm 4.4 \mathrm{ml} \cdot \mathrm{kg}^{-1} \cdot \mathrm{min}^{-1}$ to $22.6 \pm 4.9 \mathrm{ml} \cdot \mathrm{kg}^{-1} \cdot \mathrm{min}^{-1}$; follow-up: $22.6 \pm 4.9 \mathrm{ml} \cdot \mathrm{kg}^{-1} \cdot \mathrm{min}^{-1}$ vs. experimental group: $28.0 \pm 4.0 \mathrm{ml} \cdot \mathrm{kg}^{-1} \cdot \mathrm{min}^{-1}$ to $29.7 \pm 4.0$ $\mathrm{ml} . \mathrm{kg}^{-1} \cdot \mathrm{min}^{-1}$; follow-up: $\left.28.9 \pm 5.7 \mathrm{ml} \cdot \mathrm{kg}^{-1} \cdot \mathrm{min}^{-1}\right)$. Reductions in $\mathrm{z}$-score body mass index (BMI) and increases HDL-C after multidisciplinary intervention were maintained after a 6-month follow-up. In conclusion, the benefits of a multidisciplinary intervention on cardiorespiratory fitness, BMI and blood lipids are maintained after a 6-month follow-up. These findings indicate that multidisciplinary interventions produce long-term health consequences on cardiorespiratory fitness. Reinforcing the importance of lifestyle changes as a therapeutic approach for the treatment of obesity in adolescents.
\end{abstract}

\section{Keywords}

Pediatric obesity; Cardiorespiratory fitness; Physical fitness; Follow up; Adolescents.

\section{Resumo}

O objetivo do presente estudo foi investigar se os efeitos da intervenção multidisciplinar sobre a aptidão cardiorrespiratória são mantidos após um período de segmento de 6 meses em adolescentes com obesidade. Cento e sete adolescentes com obesidade foram intencionalmente alocados em dois grupos: experimental e controle. Os adolescentes do grupo experimental foram submetidos a intervenção multidisciplinar composta por acompanhamento psicológico, nutricional, clínico e treinamento aeróbio. Aptidão cardiorrespiratória (análise de gases), composição corporal (DEXA), antropometria e perfil lipídico foram avaliados no momento basal, após 24 semanas de intervenção e 6 meses após (follow up). A aptidão cardiorrespiratória reduziu no grupo controle sem alterações no grupo experimental, mesmo após o período de 6 meses (contro-

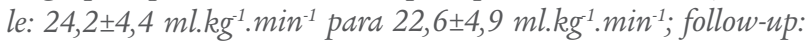
22,6 $\pm 4,9 \mathrm{ml} \cdot \mathrm{kg}^{-1} \cdot \mathrm{min}^{-1}$ vs. grupo experimental: $28,0 \pm 4,0 \mathrm{ml} \cdot \mathrm{kg}^{-1}$. $\mathrm{min}^{-1}$ para $29.7 \pm 4.0 \mathrm{ml} . \mathrm{kg}^{-1} . \mathrm{min}^{-1}$; follow-up: $28,9 \pm 5,7 \mathrm{ml} . \mathrm{kg}^{-1}$. min $\left.^{-1}\right)$. Redução no escore- $z$ do indice de massa corporal (Z-IMC) e elevação do HDL-c verificadas após 24 semanas, foram mantidas após o período de segmento. Os resultados indicam que os efeitos da intervenção multidisciplinar são mantidos após 6 meses de seguimento. Estes achados sugerem que intervenções multidisciplinares podem produzir alterações benéficas de longo prazo na capacidade cardiorrespiratória.

\section{Palavras-chave}

Obesidade infantil; Aptidão física; Seguimento; Adolescentes.
1 Graduated Program in Physical Education, University of Pernambuco, Pernambuco, Brazil; 2 University of São Paulo, Institute of Biomedical Sciences, Department of Physiology and Biophysics.

3 State University of Maringa, Paraná, Brazil.

4 Graduated Program in Human Movement Sciences and Rehabilitation, Federal University of São Paulo, Santos, Brazil.

\section{Introduction}

Obesity is a high prevalent disease in children and adolescents ${ }^{1}$, being one of the major public health issues, due to its association with premature develop- 
ment of cardiovascular diseases $(\mathrm{CVD})^{2}$. It is well-documented that multidisciplinary intervention programs (MIPs) based on lifestyle changes, including physical activity, nutritional and psychological counseling are effective in obesity management due to its short and long term effects ${ }^{3}$, and the results are improved in children and adolescents compared to adults ${ }^{4}$.

Studies have demonstrated that changes in body mass index (BMI), blood lipids, insulin, blood pressure, fatness, and waist circumference were sustained after 12 months from the end of MIPs ${ }^{5,6}$. However, to the best of our knowledge, no previous studies have investigated whether changes in cardiorespiratory fitness $(\mathrm{CrF})$ would be sustained after such interventions, which is surprising, since obese adolescents present lower $\mathrm{CrF}$ compared to their non-obese counterparts ${ }^{7}$, and $\mathrm{CrF}$ is a strong and independent predictor of CVD and all-cause of mortality in obese individuals ${ }^{8}$. Furthermore, increases in $\mathrm{CrF}$ are associated with improvements in cardiometabolic risk factors regardless of weight loss ${ }^{9}$. Thus, the primary purpose of the present study was to investigate whether changes in $\mathrm{CrF}$ are maintained 6-months following a MIP in adolescents with obesity. Secondary outcomes included anthropometry, body composition and blood lipids assessments.

\section{Methods}

\section{Participants' characteristics and recruitment}

This is a longitudinal follow-up study lasting one year. After the program was publicized in local media, 276 adolescents enrolled to participate in the study. Adolescents were included if they: a) aged between 13-18 years old; b) pubertal stage: Tanner 3-4; c) obesity: BMI > $95_{\text {th }}^{10}$.and; d) absence of hypertension, and metabolic, respiratory or genetics complications (self-reported). The Ethical Committee of the University approved the study protocol (CAEE-15798113.9.0000.5207/ CEP-UPE: 508.674/2013) and informed consent and assent were obtained from parents and adolescents respectively.

\section{Study Protocol and allocation}

Two-hundred and seventy six adolescents volunteered for the study. During the first visit to the lab, pubertal stage, height and body mass were measured. Among these, 169 did not meet the inclusion criteria. At the second visit, the adolescents underwent a medical screening and electrocardiogram (ECG) at rest and exercise. One hundred and seven adolescents were included in the final sample. At baseline, anthropometry, body composition, $\mathrm{CrF}$ and blood lipids were assessed. Participants underwent a confidential individual semi-structured interview to verify the participants' intrinsic motivation for a long-term weight loss program. The interview lasted about 20 min conducted by a psychologist and it was composed of eight questions aimed to assess personal motives for seeking weight loss treatment and barriers to losing weight. Afterwards participants were intentionally allocated into control group (CG; $n=45$ ) - those participants with the lowest intrinsic motivation; or experimental group $(E G ; n=62)$ - participants with the highest intrinsic motivation (Figure 1). All participants from EG received the same multidisciplinary intervention comprised by aerobic exercise training, nutritional, psychological and clinical counseling during 24 weeks, as previously described ${ }^{11,12}$.

\section{Multidisciplinary Intervention}

\section{- Nutritional Counseling}

A nutritionist conducted nutritional counseling for one hour each week in small 
FIGURE 1 - Flow-chart of the study

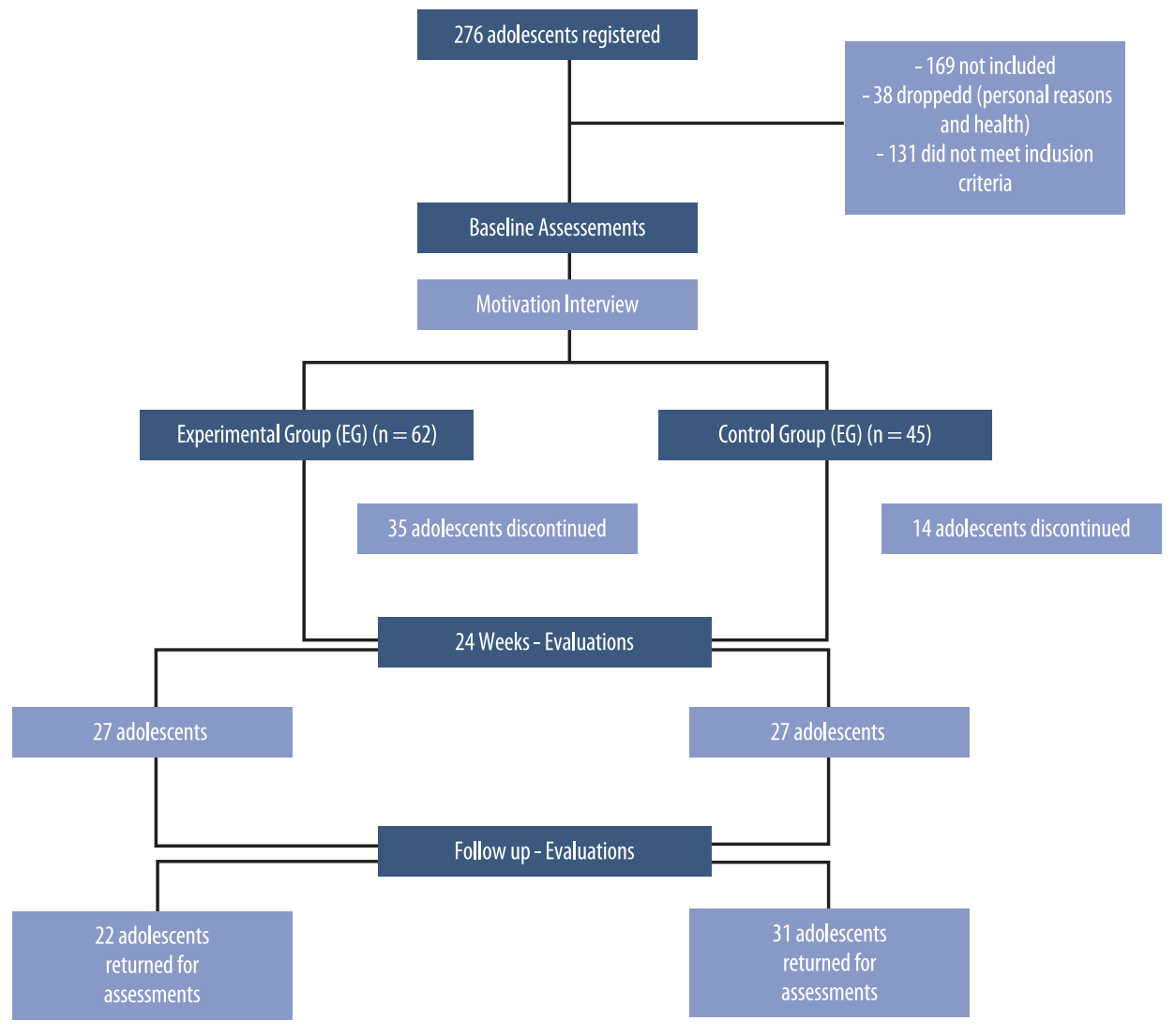

groups ( $\approx 9$ participants). Lessons focused on healthy eating behavior, weight loss diets, diet vs. light products, macro and micronutrients function, and nutritional facts. Although no specific prescription for energy intake was recommended, the participants were encouraged to reduce overall calorie intake and follow a balanced diet.

\section{- Psychological counseling}

A clinical psychologist conducted psychotherapy for one hour each week in small groups ( $\approx 9$ adolescents). Along with psychological motivation for compliance, the session themes related to body image, eating disorders (symptoms and consequences), the relationship between food and feelings, family and social problems, mood, anxiety and depression were included.

\section{- Clinical counseling}

Medical follow-up was performed once a month by an endocrinologist including a physical examination to monitor clinical parameters and to facilitate overall compliance with the study. The endocrinologist was blinded for group allocation.

\section{- Aerobic exercise training}

Under supervision of an exercise trainer, participants in EG underwent a personalized aerobic training on a treadmill, three times a week at moderate intensity. Exercise sessions were isocaloric, with energy expenditure set at $350 \mathrm{kcal}(1.050 \mathrm{kcal}$. week ${ }^{-1}$ ), estimated by indirect calorimetry. Once each participant had a specific and individualized workload, the duration of exercise sessions differed between subjects. 


\section{Measurements}

The same measurements were conducted at baseline, after 24-weeks (post-intervention), and 6 months after the end of the intervention (follow-up). In order to avoid any circadian influence, the evaluations were performed at the same period of the day by the same-trained staff team. Due to ethical reasons, adolescents allocated in CG were evaluated only at baseline and post-intervention, therefore, the post-intervention's values were imputed for the follow-up.

\section{- Anthropometry and body composition}

Body mass and height were obtained by a Filizola scale (Model 160/300, Brazil) and stadiometer (Model 160/300, Brazil), respectively. BMI was calculated by dividing body weight by squared height $\left(\mathrm{kg} \cdot \mathrm{m}^{-2}\right)$ and $\mathrm{z}$-score BMI was analyzed using the AnthroPlus-2007 tool (WHO) available: http://www.who.int/growthref/ tools/en/. Body composition was determined by dual energy $\mathrm{x}$-ray absorptiometry (DXA) in a HOLOGIC QDR WI (USA, Florida). Waist circumference was measured at the midpoint between the lower ribs and the iliac crest.

\section{- Cardiorespiratory fitness}

Oxygen uptake $\left(\mathrm{V}_{2}\right)$ was measured directly in an open circuit respiratory metabolic system (Quark, PFT, Cosmed, Italy), during a continuous incremental test on a treadmill (Cosmed T200, Italy). The greatest $\mathrm{VO}_{2}$ obtained before test interruption was considered as peak oxygen uptake $\left(\mathrm{VO}_{2 \text { peak }}\right)$. Before each test, the instruments were calibrated for gas composition $(\mathrm{O} 2=12.2 \%$ and $\mathrm{CO} 2=4.8 \%$ - White Martins) and volume (3 L Cardioequipo syringe, Brazil) following manufacturers' recommendations.

\section{- Blood sampling and assays}

Blood samples were collected in the outpatient clinic at approximately 8:00 a.m., after an overnight fast (12 hours). Serum was separated by centrifugation and stored in a deep freezer at $-80^{\circ} \mathrm{C}$ until analysis. Triglycerides, total cholesterol, high density lipoprotein (HDL-c) and glucose were determined by spectrophotometry (Cobas Integra 400 Plus), using commercially available kits (Roche). Low density lipoprotein (LDL-c) was calculated using the Friedewald's equation ${ }^{13}$.

\section{Statistical analysis}

The Gaussian distribution and the homogeneity of variance of the data were confirmed by Kolmogorov-Smirnov and Levene tests, respectively. Independent t-test was used to compare groups at baseline. The time, group, and interaction effects were assessed by a two-way ANOVA with a Tukey post-hoc when necessary. Significance was set at $p \leq 0.05$.

\section{Results}

As summarized in Table 1, general characteristics at baseline were similar between experimental groups ( $\mathrm{p}>0.05)$.

Table 2 summarizes the $\mathrm{z}$-score BMI, waist circumference, total fat mass, total free-fat mass, and body fat in the pre- and post-intervention, and at the follow-up. There was a greater decrease in $\mathrm{z}$-score BMI in the EG $(\Delta \%=-9.2 \pm 10.9 \% ; \mathrm{p}=0.02)$ compared to CG $(-2.7 \pm 7.8 \%)$ post-intervention, which was also maintained in the follow up. No changes were observed in total fat mass, waist circumference, and body fat. Fat free mass did not change in the post-intervention, however for the 
follow up it was higher only in EG.

TABLE 1 - General characteristics of the adolescents included in the present study (Recife, Brazil - 2013).

\begin{tabular}{lccc}
\hline Variables & $E G(n=62)$ & $C G(n=45)$ & $p$ \\
\hline Age (years) & $15.0 \pm 1.4$ & $14.6 \pm 1.3$ & 0.14 \\
BMl (z score) & $3.0 \pm 0.5$ & $3.0 \pm 0.5$ & 0.71 \\
WC (cm) & $97.4 \pm 9.1$ & $97.2 \pm 10.1$ & 0.91 \\
TFM (kg) & $47.3 \pm 8.2$ & $46.9 \pm 9.3$ & 0.83 \\
TLM (kg) & $44.9 \pm 7.5$ & $43.3 \pm 7.2$ & 0.27 \\
BF \% (\%) & $50.2 \pm 4.7$ & $50.4 \pm 5.0$ & 0.82 \\
TC (mg/dl) & $168.2 \pm 35.8$ & $173.2 \pm 46.1$ & 0.53 \\
LDL-c (mg/dl) & $101.2 \pm 30.1$ & $110.3 \pm 39.5$ & 0.19 \\
TG (mg/dl) & $135.3 \pm 68.4$ & $111.9 \pm 57.4$ & 0.07 \\
HDL-c (mg/dl) & $39.8 \pm 7.5$ & $40.5 \pm 10.3$ & 0.70 \\
Glucose $(\mathrm{mg} / \mathrm{dl})$ & $84.5 \pm 10.7$ & $88.8 \pm 39.8$ & 0.42 \\
VO ${ }_{2 \text { peak }}\left(\mathrm{ml} . \mathrm{kg}^{-1} \cdot \mathrm{min}^{-1}\right)$ & $25.2 \pm 4.2$ & $24.3 \pm 3.9$ & 0.27 \\
\hline
\end{tabular}

Data expressed as mean and standard deviation. Independent t-test. BMI (Z score) = Body mass index; $W C=$ Waist Circumference; $T M F=$ Total fat mass; $T L M=$ Total lean mass; BF \% = body fat percentage; TC = Total cholesterol; $\mathrm{LDL}-\mathrm{C}=\mathrm{Low}$ density lipoprotein; $\mathrm{TG}=$ Triglycerides; $\mathrm{HDL}-\mathrm{C}=$ high density lipoprotein; $\mathrm{VO}_{2 \text { peak }}=$ Peak oxygen uptake.

TABLE 2 - Anthropometric and body composition changes after a 6-months follow-up (Recife, Brazil - 2013).

\begin{tabular}{|c|c|c|c|c|c|c|}
\hline & Baseline & 24 weeks & Follow-up & Group & Time & GxT \\
\hline \multicolumn{7}{|c|}{ BMI Z-score } \\
\hline CG & $3.2 \pm 0.5$ & $3.1 \pm 0.6$ & $3.1 \pm 0.6$ & \multirow{2}{*}{0.02} & \multirow{2}{*}{$<0.01$} & \multirow{2}{*}{0.05} \\
\hline EG & $2.9 \pm 0.4$ & $2.6 \pm 0.5^{*}$ & $2.7 \pm 0.6^{*}$ & & & \\
\hline \multicolumn{7}{|c|}{ WC (cm) } \\
\hline$C G$ & $99.2 \pm 10.0$ & $100.8 \pm 9.2$ & $100.8 \pm 9.2$ & \multirow{2}{*}{0.08} & \multirow{2}{*}{0.16} & \multirow{2}{*}{0.10} \\
\hline EG & $95.7 \pm 8.8$ & $94.3 \pm 9.1$ & $96.6 \pm 9.1$ & & & \\
\hline \multicolumn{7}{|c|}{ TFM (kg) } \\
\hline CG & $48.9 \pm 9.0$ & $45.1 \pm 11.8^{*}$ & $45.1 \pm 11.8^{*}$ & \multirow{2}{*}{0.02} & \multirow{2}{*}{$<0.01$} & \multirow{2}{*}{0.31} \\
\hline EG & $43.5 \pm 5.4$ & $37.4 \pm 6.3^{*}$ & $37.8 \pm 7.8^{*}$ & & & \\
\hline \multicolumn{7}{|c|}{ TLM (kg) } \\
\hline CG & $45.0 \pm 7.3$ & $49.7 \pm 8.7^{*}$ & $49.7 \pm 8.8^{*}$ & \multirow{2}{*}{0.62} & \multirow{2}{*}{$<0.01$} & \multirow{2}{*}{$<0.01$} \\
\hline EG & $45.2 \pm 8.0$ & $49.5 \pm 7.9^{*}$ & $53.6 \pm 8.7^{* \neq}$ & & & \\
\hline \multicolumn{7}{|c|}{$\mathrm{BF} \%$} \\
\hline CG & $50.9 \pm 5.5$ & $46.3 \pm 8.3^{*}$ & $46.3 \pm 8.3^{*}$ & \multirow{2}{*}{0.04} & \multirow{2}{*}{$<0.01$} & \multirow{2}{*}{0.02} \\
\hline EG & $48.2 \pm 4.1$ & $42.0 \pm 5.6^{*}$ & $40.3 \pm 7.1^{*}$ & & & \\
\hline
\end{tabular}

* Vs. baseline; ‡ vs. 24 weeks; \# Vs control group. G = group; T = time; EG = Experimental Group; CG = control group; $W C=$ waist circumference; TFM = total fat mass; TLM = total lean mass; BF \% = percentage of body fat. Group: CG vs. EG; Time: Baseline vs. 24 weeks; GxT: interaction.

As shown in Table 3, HDL-c levels increased, whereas LDL-c and TG decreased in the post-intervention. The increase in the HDL-c was higher in the EG compared to CG $(\Delta=29.8 \pm 16.0 \%$ vs. $\Delta=18.3 \pm 11.4 \%$; $\mathrm{p}=0.02)$.

$\mathrm{CrF}$ reduced in the CG (pre-intervention: $24.2 \pm 4.4 \mathrm{ml} \cdot \mathrm{kg}^{-1} \cdot \mathrm{min}^{-1}$; post-intervention: $22.6 \pm 4.9 \mathrm{ml} \cdot \mathrm{kg}^{-1} \cdot \mathrm{min}^{-1}$; follow up: $22.6 \pm 4.9 \mathrm{ml} \cdot \mathrm{kg}^{-1} \cdot \mathrm{min}^{-1}$ ) with no changes in EG (pre-intervention: $28.0 \pm 4.0 \mathrm{ml} \cdot \mathrm{kg}^{-1} \cdot \mathrm{min}^{-1}$; post-intervention: $29.7 \pm 4.0 \mathrm{ml} \cdot \mathrm{kg}^{-1}$. $\mathrm{min}^{-1}$; follow up: $\left.28.9 \pm 5.7 \mathrm{ml} \cdot \mathrm{kg}^{-1} \cdot \mathrm{min}^{-1}\right)$. Changes in cardiorespiratory fitness were 
sustained after follow-up ( $>0.05)$. Additionally, a higher cardiorespiratory fitness was observed for EG compared to CG in the follow-up (See in Figure 2).

TABLE 3 - Changes on blood lipids of obese adolescents six months after the end of the intervention

\begin{tabular}{|c|c|c|c|c|c|c|}
\hline & Baseline & 24 weeks & Follow-up & Group & Time & GxT \\
\hline \multicolumn{7}{|c|}{$\mathrm{TC}(\mathrm{mg} / \mathrm{dl})$} \\
\hline CG & $182.0 \pm 42.5$ & $176.7 \pm 33.0$ & $176.7 \pm 33.0$ & \multirow{2}{*}{0.62} & \multirow{2}{*}{0.25} & \multirow{2}{*}{0.17} \\
\hline EG & $171.4 \pm 40.7$ & $166.9 \pm 33.2$ & $179.5 \pm 69.2$ & & & \\
\hline \multicolumn{7}{|c|}{ LDL-c (mg/dl) } \\
\hline CG & $116.2 \pm 36.3$ & $105.1 \pm 28.0^{*}$ & $105.1 \pm 28.0^{*}$ & \multirow{2}{*}{0.32} & \multirow{2}{*}{$<0.01$} & \multirow{2}{*}{0.84} \\
\hline EG & $108.1 \pm 33.9$ & $92.8 \pm 30.0^{*}$ & $93.4 \pm 39.2^{*}$ & & & \\
\hline \multicolumn{7}{|c|}{ TG (mg/dl) } \\
\hline CG & $123.8 \pm 60.3$ & $119.0 \pm 57.3^{*}$ & $119.0 \pm 57.3^{*}$ & \multirow{2}{*}{0.37} & \multirow{2}{*}{0.04} & \multirow{2}{*}{0.17} \\
\hline EG & $152.6 \pm 68.7$ & $120.7 \pm 60.3^{*}$ & $136.8 \pm 89.9^{*}$ & & & \\
\hline \multicolumn{7}{|c|}{ HDL-c (mg/dl) } \\
\hline CG & $41.1 \pm 1.9$ & $48.2 \pm 13.3^{*}$ & $48.2 \pm 13.3^{*}$ & \multirow{2}{*}{0.14} & \multirow{2}{*}{$<0.01$} & \multirow{2}{*}{$<0.01$} \\
\hline EG & $35.3 \pm 5.0$ & $45.5 \pm 6.3^{*}$ & $37.1 \pm 7.6^{*}$ & & & \\
\hline
\end{tabular}

* Vs Baseline; $\neq$ vs. 24 weeks; \# Vs control group. G = group; $T$ = time; TC = total cholesterol; LDL-C = low-density lipoprotein; TG = triglycerides; HDL-C = high-density lipoprotein; Group: CG vs. EG; Time: Baseline vs. 24 weeks; GxT: interaction.

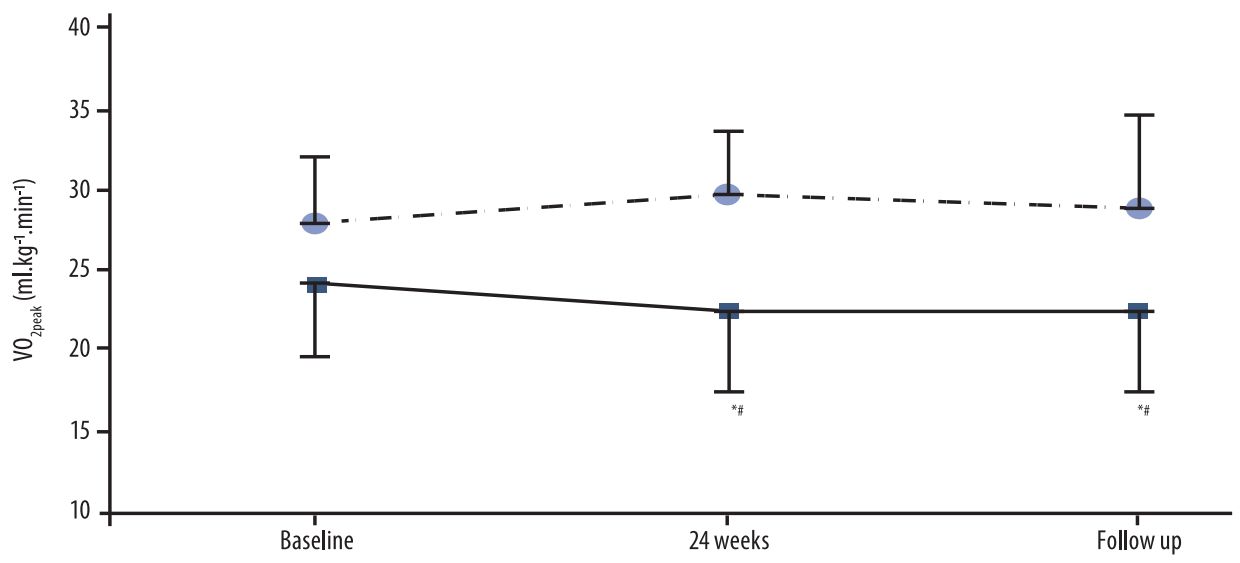

FIGURE 2 - Cardiorespiratory fitness behavior before, 24 weeks after the intervention, and 6-months of follow up in obese adolescents submitted to a multidisciplinary intervention (dotted line) or control (solid line). ${ }^{*}$ different from baseline; \#different from multidisciplinary intervention at the same moment.

\section{Discussion}

This is one of the very few studies analyzing whether the effects of a multidisciplinary intervention on cardiorespiratory fitness are maintained after 6-month follow-up in adolescents with obesity. The present study investigated whether the changes induced by MIP are sustained after the end of the intervention. Our findings revealed that improvements observed in the CrF, z-score BMI and HDL-c were preserved up to six months after the end. Some of these findings are in accordance with previous published ${ }^{6}$.

Soric et al. ${ }^{14}$, in the Zagreb Growth and Developmental Longitudinal Study, demonstrated that $\mathrm{CrF}$ did not change from age 15 to 18 years, whereas a reduction was observed from the adolescence ( 15 or 18 years old as initial observation) to middle adulthood (37 to 43 years). Similarly, Boreham et al. ${ }^{15}$ demonstrated a poor tracking for $\mathrm{CrF}$ from adolescence (15 year) to young adulthood (22 years). Conversely, the results of the present study demonstrated that obese adolescents 
from CG presented reduction in the CrF levels. Interestingly, six-months of MIP were able to sustain $\mathrm{CrF}$ levels, even during the six-months of follow-up. Therefore, these findings suggest that adolescents submitted to the MIP are prone to maintain a healthier lifestyle even after intervention. These results are particularly important because a reduced cardiorespiratory fitness is a key risk factor for metabolic diseases ${ }^{16}$. Furthermore, obese individuals with higher $\mathrm{CrF}$ have a lower risk for cardiovascular and all-cause mortality .

In fact, lower $\mathrm{CrF}$ levels are inversely associated with arterial stiffness ${ }^{17}$, which is a strong and independent predictor of cardiovascular diseases and mortality ${ }^{18}$. Thus, improvements in CrF exert very important cardioprotective effects ${ }^{19}$ and our findings highlighted the capacity of a MIP to maintain $\mathrm{CrF}$ levels over time in obese adolescents.

We also demonstrated an averaged reduction of -0.21 in $z$-score BMI in the EG at the follow-up. Kolsgaard and colleagues ${ }^{20}$ have found that decreases of $>0.10$ in this variable are associated with improvement in several cardiovascular risk factors, including lower insulin levels and better lipid profile. This is further important since insulin resistance plays an important role in the pathogenesis of numerous disease such as hypertension ${ }^{21}$, dyslipidemia ${ }^{22,23}$, hepatic steatosis ${ }^{24}$, systemic inflammation, and endothelial dysfunction ${ }^{25}$. These results are consistent with previous studies that also found decreases in z-score BMI between -0.08 and -0.24 in children and adolescents after a combined behavioral lifestyle intervention ${ }^{26,27}$.

Concerning the lipid profile, high HDL-C levels are known to be a protective

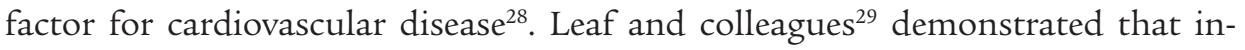
creases between 1 and $3 \mathrm{mg} / \mathrm{dL}$ of HDL-C are associated with reductions from 3\% to $6 \%$ in the risk for coronary artery disease ${ }^{29}$. We found a mean increase of $10 \mathrm{mg} /$ $\mathrm{dl}$ in this variable in the EG, suggesting a protective cardiovascular effect in these obese adolescents. In addition, the improved HDL-C levels were maintained even 6 months after the intervention, reinforcing the role of a multidisciplinary-base intervention as an efficient approach to improve the lipid profile in this population.

The present study has some limitations that should be considered. The main limitation of this study was that we did not evaluate the CG in the follow up and we cannot postulate whether adolescents would have changes during this period. In addition, we did not assess eating habits and physical activity levels at the follow-up period, which probably might have influenced the results. The intentional allocation of adolescents with low intrinsic motivation on the CG should may also influenced the outcomes, by reducing the external validation of the data, once motivation is a strong predictor of weight loss. The dropout verified in the present study should be considered in data interpretation. In contrast to the limitations, the present study employed consistent methods to assess body composition and $\mathrm{CrF}$, as well as we were able to recruit adolescents in the same maturational stage. Altogether, these characteristics are important strengths of this study.

In conclusion, the results from the present study reinforce the beneficial effects of multidisciplinary intervention on obesity management in adolescents. Nevertheless, the study points towards these effects were not limited to the intervention period. These findings have important clinical implications in the management of obesity and related comorbidities. If further studies in larger and diverse populations confirm the sustainability of such approaches, the impact on obesity treatment in adolescents should be tremendous. 


\section{Acknowledgements/Funding}

The authors thank the staff team from the 'Study Group on Nutrition and Exercise - GENE' from Pernambuco University. Special thanks for the patients and their families. We would like too to thank the CNPq and FACEPE State for financial support. The funders had no involvement in the conduct or analysis of this study. Data collection was performed by University of Pernambuco.

\section{Conflict of interest}

The authors declare no conflicts of interest

\section{Authors' contribution}

D.C. Brito (0000-0002-5320-554) and WW.L. Prado (0000-0001-5046-4522) were responsible for the initial conception, design of the study and gave significant suggestions to the manuscript improvement. A.H.G. Soares (0000-0003-03274739), T.R.S. Tenório (0000-0001-8443-1171), M.C. Lofrano-Prado (0000-00028296-3024), N. Nardo Jr (0000-0002-6862-7868), J. Donato Jr (0000-0002-61833861), M.A.M. Santos (0000-0002-2734-8416), C.T.C. Lira (0000-0002-0569-0501) e C. Terra (0000-0003-4220-5533) have made substantial contributions in data acquisition and added to further development and critical revision of the manuscript. All authors read and approved the present manuscript.

\section{References}

1. Marie N, Fleming T, Robinson M, Thomson B, Graetz N, Margono C, et al. Global, regional, and national prevalence of overweight and obesity in children and adults during 1980-2013: a systematic analysis for the Global Burden of Disease Study 2013. Lancet. 2014;384(9945):766-81.

2. Bridger T. Childhood obesity and cardiovascular disease. J Paediatr Child 2009;14(3):177.

3. Sinha A, Kling S. A review of adolescent obesity: prevalence, etiology, and treatment. Obes Surg. 2009;19(1):113-20.

4. Snethen JA, Broome ME, Cashin SE. Effective weight loss for overweight children: a meta-analysis of intervention studies. J Pediatr Nurs. 2006;21(1):45-56.

5. Schaefer A, Winkel K, Finne E, Kolip P, Reinehr T. An effective lifestyle intervention in overweight children: one-year follow-up after the randomized controlled trial on “Obeldicks light”. Clin Nutr. 2011;30(5):629-33.

6. Reinehr T, de Sousa G, Toschke AM, Andler W. Long-term follow-up of cardiovascular disease risk factors in children after an obesity intervention. Am J Clin Nutr. 2006;84(3):490-6.

7. Tenório TRdS, Farah BQ, Ritti-Dias RM, Botero JP, Brito DC, Moura PMMFd, et al. Relation between leukocyte count, adiposity, and cardiorespiratory fitness in pubertal adolescents. Einstein 2014;12(4):420-4.

8. Wei M, Kampert JB, Barlow CE, Nichaman MZ, Gibbons LW, Paffenbarger Jr RS, et al. Relationship between low cardiorespiratory fitness and mortality in normal-weight, overweight, and obese men. JAMA. 1999;282(16):1547-53.

9. Lee D-c, Artero EG, Sui X, Blair SN. Review: Mortality trends in the general population: the importance of cardiorespiratory fitness. J Psychopharmacol 2010;24(4_suppl):27-35.

10. Kuczmarski RJ, Ogden CL, Grummer-Strawn LM, Flegal KM, Guo SS, Wei R, et al. CDC growth charts: United States. Advance data. 2000(314):1-27.

11. Silva HJG, Andersen LB, Lofrano-Prado MC, Barros MV, Freitas Jr IF, Hill J, et al. Improvements on cardiovascular diseases risk factors in obese adolescents: a randomized exercise intervention study. J Phys Act Health. 2015;12(4):553-60.

12. Farah B, Ritti-Dias R, Balagopal P, Hill J, Prado W. Does exercise intensity affect blood pressure and heart rate in obese adolescents? A 6-month multidisciplinary randomized intervention study. Ped Obes. 2013;9(2):111-20. 
13. Friedewald WT, Levy RI, Fredrickson DS. Estimation of the concentration of low-density lipoprotein cholesterol in plasma, without use of the preparative ultracentrifuge. Clin Chem 1972;18(6):499-502.

14. Sorić M, Jembrek Gostović M, Gostović M, Hočevar M, Mišigoj-Duraković M. Tracking of BMI, fatness and cardiorespiratory fitness from adolescence to middle adulthood: the Zagreb Growth and Development Longitudinal Study. Ann Hum Biol. 2014;41(3):238-43.

15. Boreham C, Robson PJ, Gallagher AM, Cran GW, Savage M. Tracking of physical activity, fitness, body composition and diet from adolescence to young adulthood: The Young Hearts Project. Int J Behav Nutr Phys Act. 2004;5(1):1-14.

16. Lee S, Kuk JL, Katzmarzyk PT, Blair SN, Church TS, Ross R. Cardiorespiratory fitness attenuates metabolic risk independent of abdominal subcutaneous and visceral fat in men. Diabetes Care. 2005;28(4):895-901.

17. Silva LR, Cavaglieri C, Lopes WA, Pizzi J, Coelho-e-Silva MJ, Leite N. Endothelial wall thickness, cardiorespiratory fitness and inflammatory markers in obese and non-obese adolescents. Braz J Phys Ther. 2014;18(1):47-55.

18. 18. Vlachopoulos C, Aznaouridis K, Stefanadis C. Prediction of cardiovascular events and all-cause mortality with arterial stiffness: a systematic review and meta-analysis. $\mathrm{J}$ Am Coll Cardiol 2010;55(13):1318-27.

19. Franklin BA, McCullough PA, editors. Cardiorespiratory fitness: an independent and additive marker of risk stratification and health outcomes. Mayo Clin Proc; 2009: Elsevier.

20. Kolsgaard MLP, Joner G, Brunborg C, Anderssen SA, Tonstad S, Andersen LF. Reduction in BMI z-score and improvement in cardiometabolic risk factors in obese children and adolescents. The Oslo Adiposity Intervention Study-a hospital/public health nurse combined treatment. BMC pediatrics. 2011;11(1):47.

21. Marcovecchio ML, Patricelli L, Zito M, Capanna R, Ciampani M, Chiarelli F, et al. Ambulatory blood pressure monitoring in obese children: role of insulin resistance. J Hypertens. 2006;24(12):2431-6.

22. Farooq W, Farwa U, Khan FR. The metabolic syndrome and inflammation: role of insulin resistance and increased adiposity. Oman Med J. 2015;30(2):100.

23. Steinberger J, Daniels SR. Obesity, insulin resistance, diabetes, and cardiovascular risk in children. Circulation. 2003;107(10):1448-53.

24. D’adamo E, Impicciatore M, Capanna R, Marcovecchio ML, Masuccio FG, Chiarelli F, et al. Liver steatosis in obese prepubertal children: a possible role of insulin resistance. Obesity. 2008;16(3):677-83.

25. Dandona $\mathrm{P}$, Aljada A, Mohanty $\mathrm{P}$. The anti-inflammatory and potential anti-atherogenic effect of insulin: a new paradigm. Diabetologia. 2002;45(6):924-30.

26. Oude Luttikhuis H, Baur L, Jansen H, Shrewsbury VA, O’Malley C, Stolk RP, et al. Interventions for treating obesity in children. The Cochrane Library. 2009.

27. Summerbell CD, Waters E, Edmunds L, Kelly S, Brown T, Campbell KJ. Interventions for preventing obesity in children. Cochrane Database Syst Rev. 2005;3(3).

28. McGillicuddy FC, Reilly MP, Rader DJ. Adipose modulation of high-density lipoprotein cholesterol: implications for obesity, high-density lipoprotein metabolism, and cardiovascular disease. Circulation. 2011 Oct 11;124(15):1602-5

29. Leaf DA. The effect of physical exercise on reverse cholesterol transport. Metabolism. 2003;52(8):950-7.

Corresponding Author

Wagner L. Prado

wagner.prado@unifesp.br
Department of Human Movement

Sciences, Federal University of São

Paulo, Avenida Dona Ana Costa, 95,

Santos 11060-001, São Paulo, Brazil.

Tel. +55 13 3878-3700
Received

Revised

03/09/2017

$07 / 06 / 2017$

$10 / 07 / 2017$

Approved $\quad 21 / 07 / 2017$ 